\title{
ORIGINAL ARTICLE \\ Effects of the once-daily GLP-1 analog liraglutide on gastric emptying, glycemic parameters, appetite and energy metabolism in obese, non-diabetic adults
}

\author{
J van Can ${ }^{1}$, B Sloth ${ }^{2}$, CB Jensen ${ }^{2}$, A Flint $^{2}$, EE Blaak ${ }^{1}$ and WHM Saris ${ }^{1}$
}

\begin{abstract}
INTRODUCTION: Mechanisms for liraglutide-induced weight loss are poorly understood. OBJECTIVE: We investigated the effects of liraglutide on gastric emptying, glycemic parameters, appetite and energy metabolism in obese non-diabetic individuals.

DESIGN: Participants ( $N=49,18-75$ years, body mass index: $30-40 \mathrm{~kg} \mathrm{~m}^{-2}$ ) were randomized to two of three treatments: liraglutide $1.8 \mathrm{mg}, 3.0 \mathrm{mg}$, or placebo in a double-blind, incomplete crossover trial. After 5 weeks, 24-h energy expenditure (EE) and substrate oxidation were measured in a respiratory chamber. Gastric emptying (acetaminophen absorption method), glycemic parameters and appetite were assessed during a 5-h meal test. Ad libitum energy intake during a subsequent lunch was also assessed.

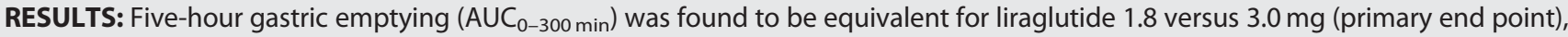
and for both liraglutide doses versus placebo, as $90 \%$ confidence intervals for the estimated treatment ratios were contained within the prespecified interval (0.80-1.25). However, 1 -h gastric emptying was $23 \%$ lower than placebo with liraglutide $3.0 \mathrm{mg}(P=0.007)$, and a nonsignificant $13 \%$ lower than placebo with liraglutide $1.8 \mathrm{mg}(P=0.14)$. Both liraglutide doses similarly reduced fasting glucose $\left(0.5-0.6 \mathrm{mmoll}^{-1}\right.$ versus placebo, $\left.P<0.0001\right)$, glucose $C_{\max }$ and 1-h AUC versus placebo; only liraglutide $3.0 \mathrm{mg}$ reduced iAUC $_{0-300 \mathrm{~min}}$ (by $\sim 26 \%$ versus placebo, $P=0.02$ ). Glucagon iAUC $\mathrm{C}_{0-300 \mathrm{~min}}$ decreased by $\sim 30 \%$, and iAUC $0-60 \mathrm{~min}$ for insulin and C-peptide was $\sim 20 \%$ lower with both liraglutide doses versus placebo. Liraglutide doses similarly increased mean postprandial satiety and fullness ratings, reduced hunger and prospective food consumption and decreased

ad libitum energy intake by $\sim 16 \%$. Liraglutide-associated reductions in EE were partly explained by a decrease in body weight. A relative shift toward increased fat and reduced carbohydrate oxidation was observed with liraglutide. Clinicaltrials.gov ID:NCT00978393. Funding: Novo Nordisk.

CONCLUSION: Gastric emptying $\mathrm{AUC}_{0-300 \mathrm{~min}}$ was equivalent for liraglutide 1.8 and $3.0 \mathrm{mg}$, and for liraglutide versus placebo, whereas reductions in $1-\mathrm{h}$ gastric emptying of $23 \%$ with liraglutide $3.0 \mathrm{mg}$ and $13 \%$ with $1.8 \mathrm{mg}$ versus placebo were observed. Liraglutide $3.0 \mathrm{mg}$ improved postprandial glycemia to a greater extent than liraglutide $1.8 \mathrm{mg}$. Liraglutide-induced weight loss appears to be mediated by reduced appetite and energy intake rather than increased $\mathrm{EE}$.
\end{abstract}

International Journal of Obesity (2014) 38, 784-793; doi:10.1038/ijo.2013.162

Keywords: postprandial glucose; energy intake; energy expenditure; substrate oxidation; weight management

\section{INTRODUCTION}

Obesity is associated with multiple metabolic abnormalities, including hyperinsulinemia, impaired glucose metabolism atherosclerosis and hypertension, which contribute to the development of type 2 diabetes mellitus (T2DM) and cardiovascular disease. ${ }^{1,2}$ Diet and life-style modification represent the first-line treatment in the management of obesity, but as these often fail to provide sustainable weight loss, pharmaceutical intervention may be necessary for the achievement of long-term, clinically relevant weight loss. ${ }^{3}$

Glucagon-like peptide-1 (GLP-1) is an incretin hormone released predominantly from the small intestine in response to food intake. In addition to reducing fasting and postprandial glycemia and enhancing glucose-dependent insulin secretion, ${ }^{4}$ GLP-1 has been shown to inhibit glucagon secretion and slow gastric emptying. ${ }^{5,6}$ Furthermore, non-clinical and clinical studies have demonstrated increased satiety, reduced food intake and subsequent reductions in body weight following administration of GLP-1, 7,8 leading to investigations into its potential for the treatment of obesity.

Liraglutide is a GLP-1 analog with $97 \%$ amino-acid sequence homology to native GLP-1. Administered by once-daily subcutaneous injection at doses up to $1.8 \mathrm{mg}$, liraglutide (Victoza) is approved for the treatment of T2DM. Liraglutide $3.0 \mathrm{mg}$ is currently under development for chronic weight management. Results from a phase 2 randomized, placebo-controlled trial of liraglutide $(1.2-3.0 \mathrm{mg})$ in 564 obese non-diabetic adults demonstrated that liraglutide $3.0 \mathrm{mg}$ was statistically significantly more effective than orlistat, or diet and exercise alone, at reducing weight over 20 and 52 weeks, and weight loss was dosedependent. ${ }^{9,10}$ In the 52-week open-label extension, completers on liraglutide 2.4 or $3.0 \mathrm{mg}$ for 2 years sustained an estimated mean weight loss of $7.8 \mathrm{~kg}$ from screening. ${ }^{10}$

${ }^{1}$ Department of Human Biology, NUTRIM, School for Nutrition, Toxicology and Metabolism, Maastricht University Medical Centre, Maastricht, The Netherlands and ${ }^{2}$ Novo Nordisk A/S, Søborg, Denmark. Correspondence: Professor WHM Saris, Department of Human Biology, NUTRIM, School for Nutrition, Toxicology and Metabolism, Maastricht University Medical Centre, Universiteitssingel 50, 6229 ER, Maastricht, The Netherlands.

E-mail: W.Saris@maastrichtuniversity.nl

Received 14 November 2012; revised 21 July 2013; accepted 8 August 2013; accepted article preview online 3 September 2013; advance online publication, 1 October 2013 
Slowing of gastric emptying, primarily within the first hour post meal, has been demonstrated with short-term liraglutide treatment at doses up to $1.8 \mathrm{mg}$ in $\mathrm{T}_{2} \mathrm{DM},{ }^{11,12}$ although no dose response between liraglutide 1.2 and $1.8 \mathrm{mg}$ was observed. ${ }^{13}$ The size of the effect on gastric emptying is not of a magnitude that necessitates dose adjustments of concomitantly administered oral medications. ${ }^{14}$ Gastric emptying has not previously been investigated with liraglutide $3.0 \mathrm{mg}$. The primary aim of the present trial was to compare the effects of liraglutide 1.8 and $3.0 \mathrm{mg}$, the maximum approved dose in treatment of type 2 diabetes and the intended clinical dose in weight management, respectively, on gastric emptying in obese individuals without T2DM, with the focus on demonstrating equivalence between the two doses over a 5-h period, in order to support that no dose adjustment of concomitantly administered oral medications would be required during treatment with liraglutide $3.0 \mathrm{mg}$. Secondary aims were to investigate and compare the effects of liraglutide 1.8 and $3.0 \mathrm{mg}$ on glucose metabolism, appetite sensations, energy intake, energy expenditure (EE) and substrate oxidation rates, and to explore the potential mechanisms for liraglutide-induced weight loss in obese individuals without T2DM.

\section{MATERIALS AND METHODS}

Participants

Men and women aged $18-75$ years with body mass index $30-40 \mathrm{~kg} \mathrm{~m}^{-2}$, stable body weight $(<5 \mathrm{~kg}$ weight change during past 3 months) and fasting blood glucose $<7.0 \mathrm{mmoll}^{-1}$ were recruited between September 2009 and April 2011. Key exclusion criteria included: diagnosis of type 1 or type 2 diabetes, use of approved weight-lowering pharmacotherapy within the previous 3 months, previous anti-obesity surgery, cardiovascular diseases and thyroid stimulating hormone outside reference range. The trial protocol was reviewed and approved by the Medical Ethical Committee of the Maastricht University Medical Centre, and all participants gave written informed consent. The trial was performed in accordance with the Declaration of Helsinki ${ }^{15}$ and ICH Good Clinical Practice. ${ }^{16}$

\section{Trial design}

This was a single-center, randomized, placebo-controlled, double-blind, two-period incomplete crossover trial. The trial design is shown in Figure 1. Before randomization, fasting blood glucose concentration was measured (EML 105 analyzer, Radiometer Medical A/S, Copenhagen, Denmark), and eligible individuals were randomized to receive two of three possible treatments (liraglutide $1.8 \mathrm{mg}, 3.0 \mathrm{mg}$, or placebo). At randomization, a dual-emission X-ray absorptiometry (DEXA) scan (Lunar Prodigy Model
DEXA, General Electric, WI, USA) was performed to determine body composition. There were two treatment periods, each consisting of 5 weeks at home plus a subsequent 2-day stay in the clinic. As the focus was on establishing the acute 'direct' effects of liraglutide, and not primarily those resulting from liraglutide-induced weight loss, participants were instructed not to change their diet, exercise program or daily routines during the trial to maintain their pre-trial body weight, and a wash-out period of 6-8 weeks was included between the two trial periods to avoid any metabolic carry-over effects of a body weight loss.

\section{Treatment}

Liraglutide $1.8 \mathrm{mg}, 3.0 \mathrm{mg}$ and placebo were administered once daily by evening subcutaneous injections, using a pre-filled injection pen, FlexPen, with $3 \mathrm{ml}$ cartridges and NovoFine needles $8 \mathrm{~mm} \times 30 \mathrm{G}$ (Novo Nordisk A/S, Bagsværd, Denmark). Dosing started at $0.6 \mathrm{mg}$ per day and increased by weekly $0.6 \mathrm{mg}$ increments to mitigate gastrointestinal side effects. Steadystate liraglutide concentrations are known to be reached after 3-5 days of treatment. ${ }^{17}$ To maintain blinding, placebo treatment was subdivided into two groups with different injection volumes, corresponding to the two liraglutide doses. Liraglutide $\left(6.0 \mathrm{mg} \mathrm{ml}^{-1}\right)$ and vehicle were provided in identical pens. Participants and investigators were thus blinded with respect to treatment (liraglutide or placebo) but not dose volume.

\section{Meal test}

After each 5-week period, a 5-h standardized breakfast meal test was performed to assess gastric emptying, postprandial glycemic parameters and subjective appetite ratings. Approximately $5 \mathrm{~h}$ after the breakfast, an ad libitum lunch meal was provided for assessment of energy intake.

After baseline blood sampling, a standardized breakfast was served. This consisted of two wholegrain Wasa crackers (Wasa AB, Stockholm, Sweden) with $10 \mathrm{~g}$ margarine and $40 \mathrm{~g}$ of full-fat Gouda cheese (totaling $250 \mathrm{kcal}$ ), a Nutrition Resource 2.0 energy drink (Nestle S.A., Vevey, Switzerland) and $200 \mathrm{ml}$ water. The drink volume was adjusted individually so that the meal's total energy content corresponded to $40 \%$ of the participant's sleeping energy expenditure, calculated during the first chamber visit. The participants started the meal with the drink, in which $1.5 \mathrm{~g}$ acetaminophen (Paracetamol 500 PCH, Pharmachemie BV, Haarlem, the Netherlands) was dissolved to assess gastric emptying. ${ }^{18,19}$ Thereafter, the two crackers (with toppings) and water were consumed, all within $15 \mathrm{~min}$. Blood samples were taken for assessment of plasma glucose, C-peptide, glucagon, acetaminophen and serum insulin concentrations. In addition, ratings for appetite (satiety, fullness, hunger and prospective food consumption), thirst, well-being and nausea were recorded using visual analog scales. ${ }^{20}$ Overall appetite score was calculated as the average of the four individual scores (satiety + fullness + (100-prospective food consumption) $+(100-$ hunger))/4. The subsequent ad libitum lunch consisted of lasagna ( $549 \mathrm{~kJ}$ $100 \mathrm{~g}^{-1} ; 33 \mathrm{E} \%$ carbohydrate, $20 \mathrm{E} \%$ protein and $47 \mathrm{E} \%$ fat) served with

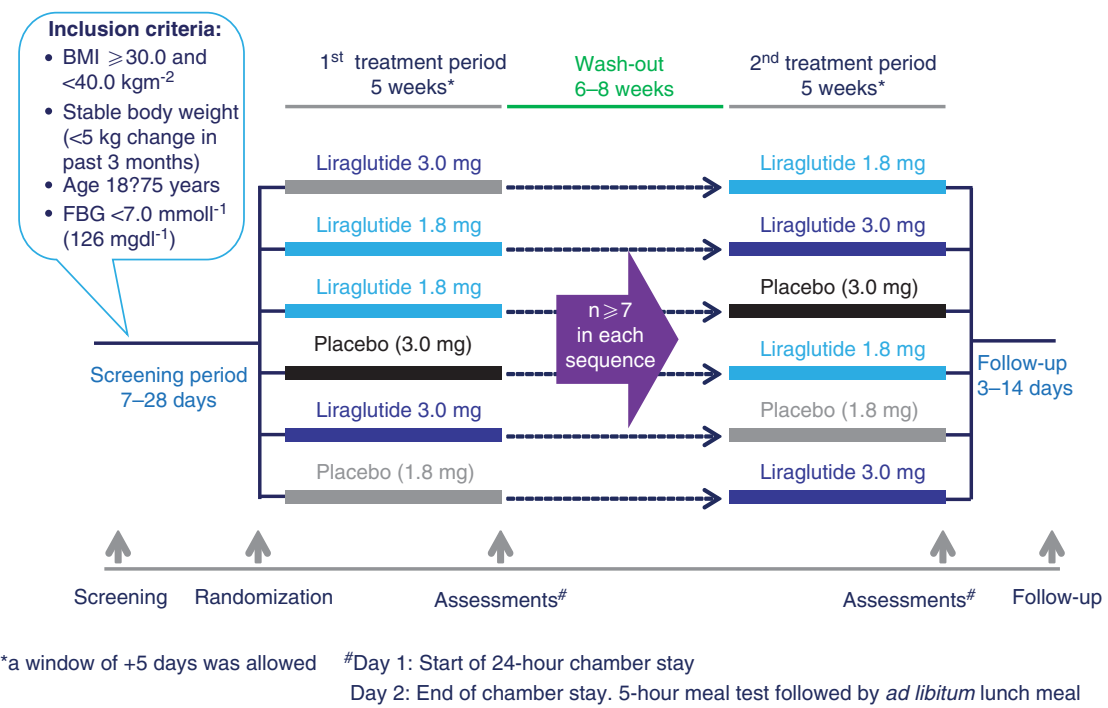

Figure 1. Trial design FBG, fasting blood glucose. 
$200 \mathrm{ml}$ water. Participants were instructed to eat until pleasantly satiated and the meal was to be completed within $30 \mathrm{~min}$.

Acetaminophen absorption is an indirect assessment of the liquid phase of gastric emptying. Orally administered acetaminophen is poorly absorbed by the stomach but absorbed rapidly from the small intestine. Thus, gastric emptying is the rate-limiting step for the appearance of acetaminophen in the blood. ${ }^{18}$ The maximum concentration $\left(C_{\max }\right)$ of acetaminophen is reached after $30-60 \mathrm{~min}$ and $t \frac{1}{2}$ is approximately $2 \mathrm{~h}$. Therefore, $60 \mathrm{~min}$ AUC is a marker of the rapidity of gastric emptying and 300 min AUC a marker of gastric emptying totality.

\section{Respiratory chamber}

Twenty-four hours EE and substrate oxidation rates were assessed during a 24-h stay in an open-circuit respiratory chamber ${ }^{21}$ during the 2-day stay in the clinic at the end of each treatment period. Participants arrived in the evening and stayed overnight to get accustomed to the chamber and to enable the measurement of sleeping energy expenditure (used to calculate energy requirements for the 24-h stay).

Gas exchange was calculated from oxygen consumption and carbon dioxide production in the respiratory chamber. The room was ventilated with fresh air at a rate of $70-801 \mathrm{~min}^{-1}$ and was measured with a dry gas meter (Schlumberger, type G6, Delft, the Netherlands). Oxygen and carbon dioxide concentrations were measured using paramagnetic oxygen analyzers (Magnos G6 and Uras 3G, Hartmann \& Braun, Frankfurt, Germany). During each 15-min period, six samples of outgoing air for each chamber and one sample each of fresh air, zero gas and calibration gas were selected and recorded by computer. Twenty-four hours EE, 24-h carbohydrate, fat and protein oxidation rates and 24-h respiratory quotient were calculated from oxygen consumption and carbon dioxide production. ${ }^{22,23}$ Energy balance was calculated as $24-\mathrm{h}$ energy intake minus EE. During both chamber stays, 24-h urinary nitrogen, adrenalin and noradrenalin concentrations were measured. The nitrogen excreted in the urine was used in the protein oxidation calculation.

During daytime, participants had three exercise periods of bench stepping for $3 \times 5 \mathrm{~min}$. Physical activity was monitored with a radar system using the Doppler principle. For the calculation of activity-induced $E E, E E$ was plotted against radar output and averaged over 30-min periods. The intercept of the regression line at lowest radar output represented resting energy expenditure (REE). Activity-induced $\mathrm{EE}$ was calculated by subtracting resting metabolic rate from $24-\mathrm{h} \mathrm{EE}^{24,25}$ Physical activity level was calculated by dividing 24-h EE by sleeping energy expenditure with the lowest radar output. ${ }^{26}$

\section{Safety assessments}

Safety assessments included adverse events, medical history, vital signs, electrocardiogram, physical examination, standard safety laboratory assessments and lipase, amylase and calcitonin measurements. Twentyfour hours heart rate was measured in the respiratory chamber using a heart rate monitoring system (Polar Electro Oy, Kempele, Finland) with 1 -min intervals.

\section{Statistical analysis}

The primary end point of the trial was gastric emptying, assessed as $\mathrm{AUC}_{0-300 \mathrm{~min}}$ of acetaminophen postprandial concentration profiles during the standardized meal test. The liraglutide 3.0 and $1.8 \mathrm{mg}$ groups were to be declared equivalent with respect to gastric emptying if the two-sided $90 \%$ confidence interval $(\mathrm{Cl})$ for the estimated ratio of acetaminophen $\mathrm{AUC}_{0-300 \mathrm{~min}}$ between the two groups was fully contained within the interval 0.80-1.25.

Sample size estimation was based on a previous clinical trial, ${ }^{11}$ in which the within-subject variance of $\log \left(\mathrm{AUC}_{0-300 \mathrm{~min}}\right)$ for acetaminophen was estimated to be $\sim 0.03$ and the between-subject variance, 0.04 . On the basis of this, 10000 simulations were run based on different true ratios (1.00 to 1.15) and on 48 and 42 individuals in total. Assuming the true ratio to be no more than $1.10,48$ individuals were planned to be randomized and at least 7 participants had to complete each sequence.

The full analysis set of all randomized individuals and the safety analysis set (all individuals receiving at least one dose of trial product) were the same and therefore used for all efficacy and safety evaluations. $A \cup C_{0-300 \mathrm{~min}}$ and incremental $A \cup C_{0-300 \mathrm{~min}}\left(\mathrm{i} \mathrm{AUC} \mathrm{C}_{0-300 \mathrm{~min}}\right.$ ) were calculated using the trapezoidal method. For the log-transformed meal test end points (all except iAUC), the estimated treatment differences and the corresponding $\mathrm{Cl}$ were back-transformed to the original scale and presented as the ratio between liraglutide and placebo, with corresponding $95 \% \mathrm{Cls}$. Mean differences or ratios between treatment groups were estimated using a parametric linear mixed-effect model that included period and treatment group as fixed effects, and subject as a random effect. Statistical analysis of all secondary end points was two-sided and on a $5 \%$ significance level.

For 24-h EE and substrate oxidation rates, exploratory post hoc analyses were performed to investigate which factors might have contributed to the observed difference between liraglutide treatments and placebo.

\section{RESULTS}

Trial population

Of 62 screened individuals, 49 (29 males and 20 females) were randomized and were exposed to trial drug. Of these, 44 completed the trial and 5 withdrew; 2 because of AEs (toe thrombosis and tooth infection) and 3 due to other reasons (spouse health problems [2] and discomfort in the respiratory chamber). All 49 individuals exposed to trial product were included in the analysis set. It should be noted that two participants missed a single dose 3 and 4 days, respectively, before the assessment visit (but were included in the analyses). Participants were of mean ( \pm s.d.) age $48.3 \pm 13.2$ years, height $1.72 \pm 0.09 \mathrm{~m}$, weight $102.0 \pm 13.9 \mathrm{~kg}$, body mass index $34.2 \pm 2.7 \mathrm{~kg} \mathrm{~m}^{-2}$ and fat mass $33.1 \pm 7.1 \%$; mean fasting blood glucose was $5.4 \pm 0.55 \mathrm{mmoll}^{-1}$. Estimated mean 5 -week weight losses of $2.1 \mathrm{~kg}(95 \% \mathrm{Cl}-3.2 ;-1.1)$ and $2.5 \mathrm{~kg}(-3.5 ;-1.4)$ were observed from randomization with liraglutide $1.8 \mathrm{mg}$ and $3.0 \mathrm{mg}$, respectively, compared with placebo $(P<0.001)$ (Supplementary Table 2).

\section{Gastric emptying}

Five-hour acetaminophen concentration-time profiles are shown in Figure 2. Equivalence in gastric emptying (acetaminophen $\mathrm{AUC}_{0-300 \mathrm{~min}}$ ) at the end of the 5-week treatment periods was observed for liraglutide $1.8 \mathrm{mg}$ versus $3.0 \mathrm{mg}$, and liraglutide versus placebo, as $90 \% \mathrm{Cls}$ for the estimated ratios were fully contained within the interval $(0.80-1.25)$ (Table 1$)$. No statistically significant treatment differences in the ratio $\mathrm{AUC}_{0-60 \mathrm{~min}} /$ $\mathrm{AUC}_{0-300 \mathrm{~min}}$ were likewise observed. Mean $\mathrm{AUC}_{0-60 \mathrm{~min}}$ was reduced by $23 \%(P=0.007)$ with liraglutide $3.0 \mathrm{mg}$ and $13 \%$ $(P=0.14)$ with liraglutide $1.8 \mathrm{mg}$ compared with placebo. The maximum concentration $\left(C_{\max }\right)$ was lower with liraglutide $1.8 \mathrm{mg}$ versus placebo $(P=0.04)$ (Table 1$)$.

\section{Glycemic parameters}

Mean fasting plasma glucose concentrations decreased by $0.5-0.6 \mathrm{mmoll}^{-1}$ with both liraglutide 1.8 and $3.0 \mathrm{mg}$ compared with placebo $(P<0.0001)$ (Table 2$)$. There were no statistically

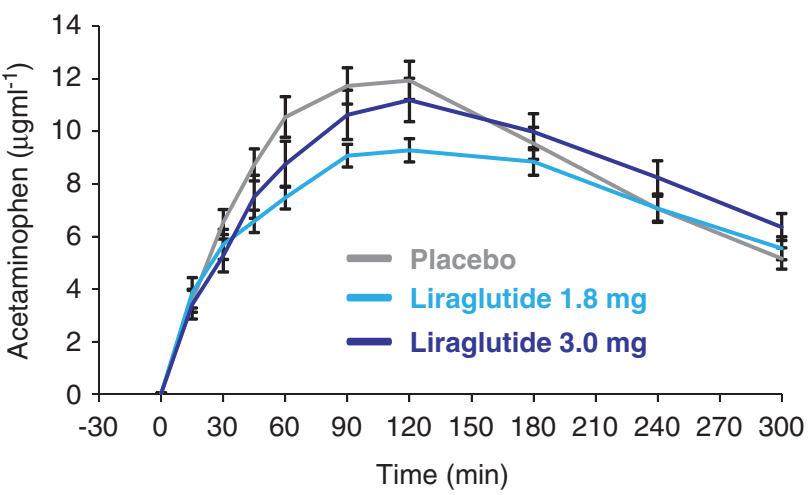

Figure 2. Effect of liraglutide and placebo on gastric emptying. Data are presented as mean \pm s.e. 
Table 1. Comparison of estimated means and treatment differences for gastric emptying after 5 weeks of treatment

\begin{tabular}{|c|c|c|c|c|c|}
\hline Parameters & $\begin{array}{l}\text { Liraglutide } 1.8 \mathrm{mg} \\
\qquad \mathrm{n}=30\end{array}$ & $\begin{array}{l}\text { Liraglutide } 3.0 \mathrm{mg} \\
\qquad \mathrm{n}=30\end{array}$ & $\begin{array}{c}\text { Placebo } \\
\mathrm{n}=30\end{array}$ & $\begin{array}{l}\text { Treatment ratio }(R) \text { for } \\
{ }^{1} \text { liraglutide } 1.8 \mathrm{mg}^{2} \text { vs placebo }{ }^{2} \text { liraglutide } \\
3.0 \mathrm{mg} \text { vs placebo }{ }^{3} \text { liraglutide } 3.0 \text { vs } 1.8 \mathrm{mg}\end{array}$ & P-value \\
\hline \multicolumn{6}{|l|}{ Gastric emptying } \\
\hline \multirow[t]{3}{*}{$\mathrm{AUC}_{0-300 \min }\left(\min \mu \mathrm{g} \mathrm{ml}^{-1}\right)$} & 2193 & 2252 & 2424 & & \\
\hline & & & & ${ }^{1} \mathrm{R}: 0.90(0.81 ; 1.01)$ & 0.15 \\
\hline & & & & ${ }^{2} \mathrm{R}: 0.93(0.83 ; 1.04)$ & 0.28 \\
\hline \multirow{5}{*}{$\begin{array}{l}\text { Primary end point: } \\
\text { AUC }_{0-60 \min }\left(\min \mu \mathrm{gl}^{-1}\right)\end{array}$} & & & & ${ }^{3} \mathrm{R}: 1.03(0.92 ; 1.15)$ & 0.69 \\
\hline & 299.4 & 265.2 & 343.1 & & \\
\hline & & & & ${ }^{1} \mathrm{R}: 0.87$ (0.73; 1.05) & 0.14 \\
\hline & & & & ${ }^{2} \mathrm{R}: 0.77(0.64 ; 0.93)$ & 0.007 \\
\hline & & & & ${ }^{3} \mathrm{R}: 0.89(0.74 ; 1.06)$ & 0.18 \\
\hline \multirow[t]{4}{*}{ Ratio $A U C_{0-60 \mathrm{~min}} / \mathrm{AUC}_{0-300 \mathrm{~min}}$} & 0.13 & 0.12 & 0.14 & & \\
\hline & & & & ${ }^{1} \mathrm{R}: 0.94(0.75 ; 1.18)$ & 0.61 \\
\hline & & & & ²R: $0.84(0.67 ; 1.05)$ & 0.12 \\
\hline & & & & ${ }^{3} \mathrm{R}: 0.89(0.71 ; 1.11)$ & 0.29 \\
\hline \multirow[t]{4}{*}{$C_{\max }\left(\mu \mathrm{g} \mathrm{ml}^{-1}\right)$} & 10.5 & 11.4 & 11.8 & & \\
\hline & & & & ${ }^{1} \mathrm{R}: 0.90(0.81 ; 0.99)$ & 0.04 \\
\hline & & & & ${ }^{2} \mathrm{R}: 0.97(0.87 ; 1.07)$ & 0.52 \\
\hline & & & & ${ }^{3} \mathrm{R}: 1.08(0.97 ; 1.20)$ & 0.14 \\
\hline
\end{tabular}

Abbreviation: $\mathrm{Cl}$, confidence interval. Data are estimated means. Treatment ratios are estimated means $(95 \% \mathrm{Cls})$, except for primary end point $\mathrm{AUC} \mathrm{C}_{0-300 \text { min }}$, where they are estimated means $(90 \% \mathrm{Cls})$. Comparisons between treatment groups were performed using the parametric linear mixed-effect model using log-transformed values. The model included effects of subject, period and treatment group (subject was included as a random effect).

significant differences in mean fasting glucagon, insulin or C-peptide concentrations between treatments.

Postprandial 5-h profiles are shown in Figure 3. Both liraglutide doses similarly reduced glucose AUC in the first hour of the meal $\left(A_{U} C_{0-60 \min }\right)$ and $C_{\max }$ compared with placebo (Table 2), whereas no statistically significant differences were observed in the incremental 1 -h response ( iAUC $_{0-60 \mathrm{~min}}$ ) between treatments. Interestingly, only liraglutide $3.0 \mathrm{mg}$ reduced the mean 5 -h AUC $\left(\mathrm{AUC}_{0-300 \mathrm{~min}}\right.$ ) and $\mathrm{iAUC}$ (iAUC $\mathrm{i}_{0-300 \mathrm{~min}}$ ) by $13 \%$ (versus placebo, $P=0.002$ ) and $\sim 26 \%$ (versus placebo and liraglutide $1.8 \mathrm{mg}$, $P=0.002)$, respectively.

For glucagon, liraglutide 1.8 and $3.0 \mathrm{mg}$ similarly reduced the total and incremental postprandial responses in the initial phase as well as during the entire 5 - $h$ period, including a reduction in iAUC $_{0-300 \text { min }}$ of $\sim 30 \%$ compared with placebo (Table 2 ).

Likewise, liraglutide 1.8 and $3.0 \mathrm{mg}$ were associated with similar reductions in total and incremental insulin and C-peptide AUCs in the first hour, including reductions in insulin and C-peptide $\mathrm{iAUC}_{0-60 \mathrm{~min}}$ of $\sim 20 \%$ compared with placebo (Table 2). No treatment differences were observed for $C_{\max }, A U C_{0-300 \text { min, }}$ or $\mathrm{i} A U C_{0-300 \text { min }}$.

Subjective visual analog scale ratings of appetite, thirst, well-being and nausea

Appetite ratings during the 5 -h meal test are shown in Figure 4. Mean fasting ratings for overall appetite score and individual appetite components were comparable in all treatment groups (Supplementary Table 1 ). Mean ratings $\left(A \cup C_{15-300 \mathrm{~min}} / 285 \mathrm{~min}\right.$ ), maximum ratings and 15 -min postprandial ratings were statistically significantly and similarly increased with liraglutide 1.8 and $3.0 \mathrm{mg}$ compared with placebo for overall appetite score (indicating reduced appetite), satiety, fullness and '100-prospective food consumption' (indicating reduced prospective consumption). For '100-hunger', only the mean postprandial rating was statistically significantly increased with liraglutide 1.8 and $3.0 \mathrm{mg}$ versus placebo (indicating reduced hunger). For nausea, only the mean fasting rating was significantly greater with liraglutide $3.0 \mathrm{mg}$ compared with both placebo and liraglutide $1.8 \mathrm{mg}$; no differences in mean postprandial ratings between liraglutide doses and placebo were observed. The mean postprandial thirst rating $\left(A \cup C_{15-300 \mathrm{~min}} / 285 \mathrm{~min}\right.$ ) was similarly decreased with liraglutide 1.8 and $3.0 \mathrm{mg}$ compared with placebo (estimated difference $-10 \mathrm{~mm}(95 \% \mathrm{Cl}-19 ;-1) ; P=0.03$ for both doses). No significant treatment differences were observed for other thirst ratings or well-being ratings (data not shown).

\section{Energy intake}

Mean estimated energy intake during the ad libitum lunch was reduced by 588 and $568 \mathrm{~kJ}(\sim 16 \%)$ with liraglutide $1.8 \mathrm{mg}$ $(P=0.002)$ and $3.0 \mathrm{mg}(P=0.003)$, respectively, compared with placebo (Figure 4).

\section{EE and substrate oxidation rates}

In the respiratory chamber, all treatment groups had a slightly negative 24 -h energy balance (mean -4.6 to $-2.8 \%$ ), which reached statistical significance for liraglutide $1.8 \mathrm{mg}$ versus placebo (Supplementary Table 2), although energy balance for all participants was within an acceptable $10 \%$ limit (range -10.0 to $6.2 \%) .{ }^{27}$ Mean 24-h EE was lower with both liraglutide doses compared with placebo, $350 \mathrm{~kJ}$ per $24 \mathrm{~h}(\sim 3 \%, P=0.02)$ and $581 \mathrm{~kJ}$ per $24 \mathrm{~h}(\sim 5 \%, P=0.0001)$ for liraglutide $1.8 \mathrm{mg}$ and $3.0 \mathrm{mg}$, respectively (Figure 5; Supplementary Table 2). Similarly, sleeping metabolic rate (defined as 3-h EE during the period with lowest spontaneous physical activity (a surrogate marker of REE)) was lower for liraglutide 1.8 and $3.0 \mathrm{mg}$ versus placebo $(\sim 3 \%$, $P=0.04$ and $P=0.05$, respectively). The activity-related end points physical activity level and activity-induced EE decreased with liraglutide $3.0 \mathrm{mg}$ compared with placebo, but only the difference in mean activity-induced EE was statistically significant $(P=0.03)$. By adding change in body weight after 5 weeks of treatment as a covariate to the statistical model in a post hoc analysis, the treatment-related differences in 24-h EE as described above were reduced $(\sim 2 \%, P=0.21$ and $\sim 3 \%, P=0.02$ for liraglutide $1.8 \mathrm{mg}$ and $3.0 \mathrm{mg}$ versus placebo, respectively; Supplementary Table 2).

Mean 24-h respiratory quotient was reduced with liraglutide $1.8 \mathrm{mg}$ compared with placebo $(P<0.0001)$ and a similar trend $(P=0.09)$ was observed for liraglutide $3.0 \mathrm{mg}$ (Supplementary Table 2). The lower respiratory quotient with liraglutide translated into statistically significantly increased fat oxidation with liraglutide $1.8 \mathrm{mg}$ at the expense of significantly lower mean carbohydrate and protein oxidation with both liraglutide doses versus placebo. Post hoc analyses of substrate oxidation rates, which 
Table 2. Comparison of estimated means and treatment differences for glycemic parameters after 5 weeks of treatment

\begin{tabular}{|c|c|c|c|c|c|}
\hline Parameters & $\begin{array}{l}\text { Liraglutide } 1.8 \mathrm{mg} \\
\qquad \mathrm{n}=30\end{array}$ & $\begin{array}{l}\text { Liraglutide } 3.0 \mathrm{mg} \\
\qquad \mathrm{n}=30\end{array}$ & $\begin{array}{c}\text { Placebo } \\
\mathrm{n}=30\end{array}$ & $\begin{array}{l}\text { Treatment ratio }(R) \text { or difference } \\
(D) \text { for }{ }^{7} \text { liraglutide } 1.8 \mathrm{mg} \text { vs } \\
\text { placebo }{ }^{2} \text { liraglutide } 3.0 \mathrm{mg} \text { vs } \\
\text { placebo }{ }^{3} \text { liraglutide } 3.0 \mathrm{vs} 1.8 \mathrm{mg}\end{array}$ & P-value \\
\hline \multicolumn{6}{|l|}{ Glucose } \\
\hline \multirow{4}{*}{$\begin{array}{l}\text { Fasting plasma }\left(\mathrm{mmoll}^{-1}\right) \\
\text { glucose }\end{array}$} & 4.9 & 4.9 & 5.4 & & \\
\hline & & & & ${ }^{1} \mathrm{R}: 0.89(0.86 ; 0.93)$ & $<0.0001$ \\
\hline & & & & ${ }^{2} \mathrm{R}: 0.90(0.87 ; 0.94)$ & $<0.0001$ \\
\hline & & & & ${ }^{3} \mathrm{R}: 1.01$ (0.97; 1.05) & 0.70 \\
\hline \multicolumn{6}{|l|}{ Postprandial values } \\
\hline \multirow{4}{*}{$\begin{array}{l}\text { AUC } C_{0-300 ~ m i n} \\
\left(\left(\operatorname{min~mmoll}{ }^{-1}\right)\right.\end{array}$} & 1648 & 1532 & 1767 & & \\
\hline & & & & ${ }^{1} \mathrm{R}: 0.93(0.85 ; 1.02)$ & 0.12 \\
\hline & & & & ${ }^{2} \mathrm{R}: 0.87$ (0.79; 0.95) & 0.002 \\
\hline & & & & ${ }^{3} \mathrm{R}: 0.93(0.85 ; 1.01)$ & 0.10 \\
\hline \multirow{4}{*}{$\begin{array}{l}\mathrm{iAUC}_{0-300 \mathrm{~min}} \\
\left(\mathrm{~min} \mathrm{mmolI^{-1 }}\right)\end{array}$} & 191.8 & 143.0 & 192.2 & & \\
\hline & & & & ${ }^{1} \mathrm{D}:-0.4(-40.8 ; 40.1)$ & 0.99 \\
\hline & & & & ${ }^{2} \mathrm{D}:-49.1(-89.6 ;-8.7)$ & 0.02 \\
\hline & & & & ${ }^{3} \mathrm{D}:-48.8(-88.7 ;-8.9)$ & 0.02 \\
\hline \multirow{4}{*}{ 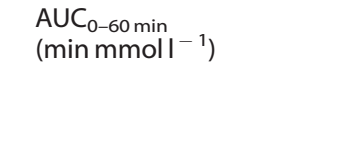 } & 388.4 & 386.0 & 425.2 & & \\
\hline & & & & ${ }^{1} \mathrm{R}: 0.91(0.87 ; 0.96)$ & 0.0003 \\
\hline & & & & ${ }^{2} \mathrm{R}: 0.91(0.87 ; 0.95)$ & 0.0001 \\
\hline & & & & ${ }^{3} \mathrm{R}: 0.99$ (0.95; 1.04) & 0.78 \\
\hline \multirow{4}{*}{$\begin{array}{l}\mathrm{iAUC}_{0-60 \mathrm{~min}} \\
\left(\mathrm{~min} \mathrm{mmoll} \mathrm{mm}^{-1}\right)\end{array}$} & 76.3 & 67.0 & 76.7 & & \\
\hline & & & & ${ }^{1} \mathrm{D}:-0.4(-16.0 ; 15.2)$ & 0.96 \\
\hline & & & & ${ }^{2} \mathrm{D}:-9.7(-25.2 ; 5.9)$ & 0.22 \\
\hline & & & & ${ }^{3} \mathrm{D}:-9.3(-24.6 ; 6.1)$ & 0.23 \\
\hline \multirow[t]{4}{*}{$C_{\max }\left(\mathrm{mmoll}^{-1}\right)$} & 7.0 & 6.8 & 7.5 & & \\
\hline & & & & ${ }^{1} \mathrm{R}: 0.94$ (0.88; 1.00) & 0.04 \\
\hline & & & & ${ }^{2} \mathrm{R}: 0.91(0.85 ; 0.96)$ & 0.003 \\
\hline & & & & ${ }^{3} \mathrm{R}: 0.97(0.91 ; 1.03)$ & 0.30 \\
\hline \multicolumn{6}{|l|}{ Glucagon } \\
\hline \multirow{4}{*}{$\begin{array}{l}\text { Fasting plasma }\left(\mathrm{pg} \mathrm{ml}^{-1}\right) \\
\text { glucagon }\end{array}$} & 106.5 & 109.5 & 108.5 & & \\
\hline & & & & ${ }^{1} \mathrm{R}: 0.98$ (0.90; 1.07) & 0.66 \\
\hline & & & & ${ }^{2} \mathrm{R}: 1.01$ (0.93; 1.10) & 0.83 \\
\hline & & & & ${ }^{3} \mathrm{R}: 1.03(0.95 ; 1.12)$ & 0.51 \\
\hline \multicolumn{6}{|l|}{ Postprandial values } \\
\hline \multirow{4}{*}{$\begin{array}{l}A \cup C_{0-300 \min } \\
\left(\operatorname{min~pg~ml}^{-1}\right)\end{array}$} & 36011 & 35657 & 40618 & & \\
\hline & & & & ${ }^{1} \mathrm{R}: 0.89(0.81 ; 0.97)$ & 0.01 \\
\hline & & & & ${ }^{2} \mathrm{R}: 0.88(0.80 ; 0.96)$ & 0.007 \\
\hline & & & & ${ }^{3} \mathrm{R}: 0.99(0.90 ; 1.09)$ & 0.83 \\
\hline \multirow{4}{*}{$\begin{array}{l}\mathrm{iAUC} \mathrm{C}_{0-300 \min } \\
\left(\operatorname{min~pg~ml}^{-1}\right)\end{array}$} & 4781 & 4866 & 6957 & & \\
\hline & & & & ${ }^{1} \mathrm{D}:-2176(-4277 ;-74.6)$ & 0.04 \\
\hline & & & & ${ }^{2} \mathrm{D}:-2091(-4191 ; 10.1)$ & 0.051 \\
\hline & & & & ${ }^{3} \mathrm{D}: 85.3(-2000 ; 2171)$ & 0.94 \\
\hline \multirow{4}{*}{$A \cup C_{0-60 \min }\left(\min \mathrm{pg} \mathrm{ml}^{-1}\right)$} & 8244 & 8500 & 8902 & & \\
\hline & & & & ${ }^{1} \mathrm{R}: 0.93(0.87 ; 0.98)$ & 0.01 \\
\hline & & & & ${ }^{2} \mathrm{R}: 0.95(0.90 ; 1.01)$ & 0.12 \\
\hline & & & & ${ }^{3} \mathrm{R}: 1.03(0.97 ; 1.09)$ & 0.30 \\
\hline \multirow[t]{4}{*}{$\mathrm{i} A \cup C_{0-60 \min }\left(\min \mathrm{pg} \mathrm{ml}^{-1}\right)$} & 1294 & 1460 & 1688 & & \\
\hline & & & & ${ }^{1} \mathrm{D}:-394(-891 ; 102.6)$ & 0.12 \\
\hline & & & & ${ }^{2} \mathrm{D}:-227(-724 ; 269.3)$ & 0.36 \\
\hline & & & & ${ }^{3} \mathrm{D}: 166.8(-328 ; 661.5)$ & 0.50 \\
\hline \multirow[t]{4}{*}{$\mathrm{C}_{\max }\left(\mathrm{pg} \mathrm{ml^{-1 }}\right)$} & 145.5 & 147.0 & 156.9 & & \\
\hline & & & & ${ }^{1} \mathrm{R}: 0.93$ (0.87; 0.99) & 0.03 \\
\hline & & & & ${ }^{2} \mathrm{R}: 0.94(0.88 ; 1.00)$ & 0.06 \\
\hline & & & & ${ }^{3} \mathrm{R}: 1.01$ (0.95; 1.08) & 0.75 \\
\hline \multicolumn{6}{|l|}{ Insulin } \\
\hline Fasting serum $\left(\mathrm{mUl}^{-1}\right)$ & 11.4 & 12.7 & 10.8 & & \\
\hline insulin & & & & ${ }^{1} \mathrm{R}: 1.05$ (0.87; 1.28) & 0.58 \\
\hline & & & & ${ }^{2} \mathrm{R}: 1.18$ (0.97; 1.43) & 0.10 \\
\hline & & & & ${ }^{3} \mathrm{R}: 1.12(0.92 ; 1.35)$ & 0.25 \\
\hline
\end{tabular}




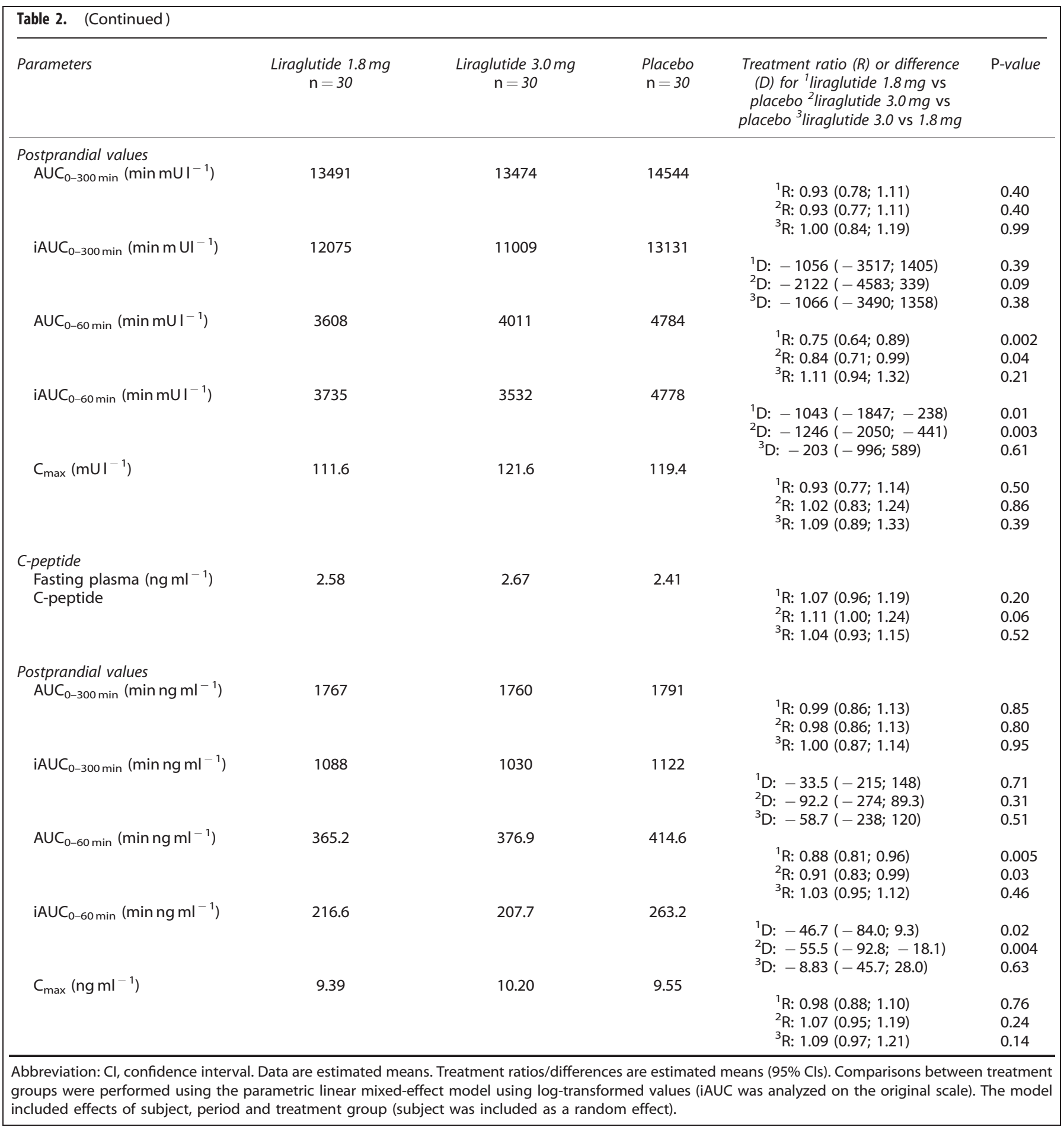

adjusted for gender and energy balance, confirmed the relative shift in 24-h substrate oxidation toward fat oxidation with liraglutide treatment. The treatment-related decreases in protein oxidation were, however, no longer statistically significant.

Urinary 24-h noradrenalin excretion was reduced with both liraglutide $1.8 \mathrm{mg}$ (estimated ratio $0.9(95 \% \mathrm{Cl} 0.8 ; 1.0), P=0.02)$ and $3.0 \mathrm{mg}$ (ratio $0.9(0.8 ; 1.0), P=0.03$ ) compared with placebo. No treatment differences were observed for adrenalin (data not shown).
Safety

Overall, liraglutide was well tolerated and no safety concerns were identified. The proportion of individuals reporting AEs, which were all of mild or moderate severity, was similar for liraglutide $1.8 \mathrm{mg}$ (90\%) and $3.0 \mathrm{mg}(94 \%)$, and lower (75\%) for placebo. Decreased appetite and gastrointestinal disorders (most commonly nausea) were reported more frequently with liraglutide (Supplementary Table 3). One serious adverse event (toe thrombosis) was reported in the liraglutide $3.0 \mathrm{mg}$ group and led to withdrawal. 

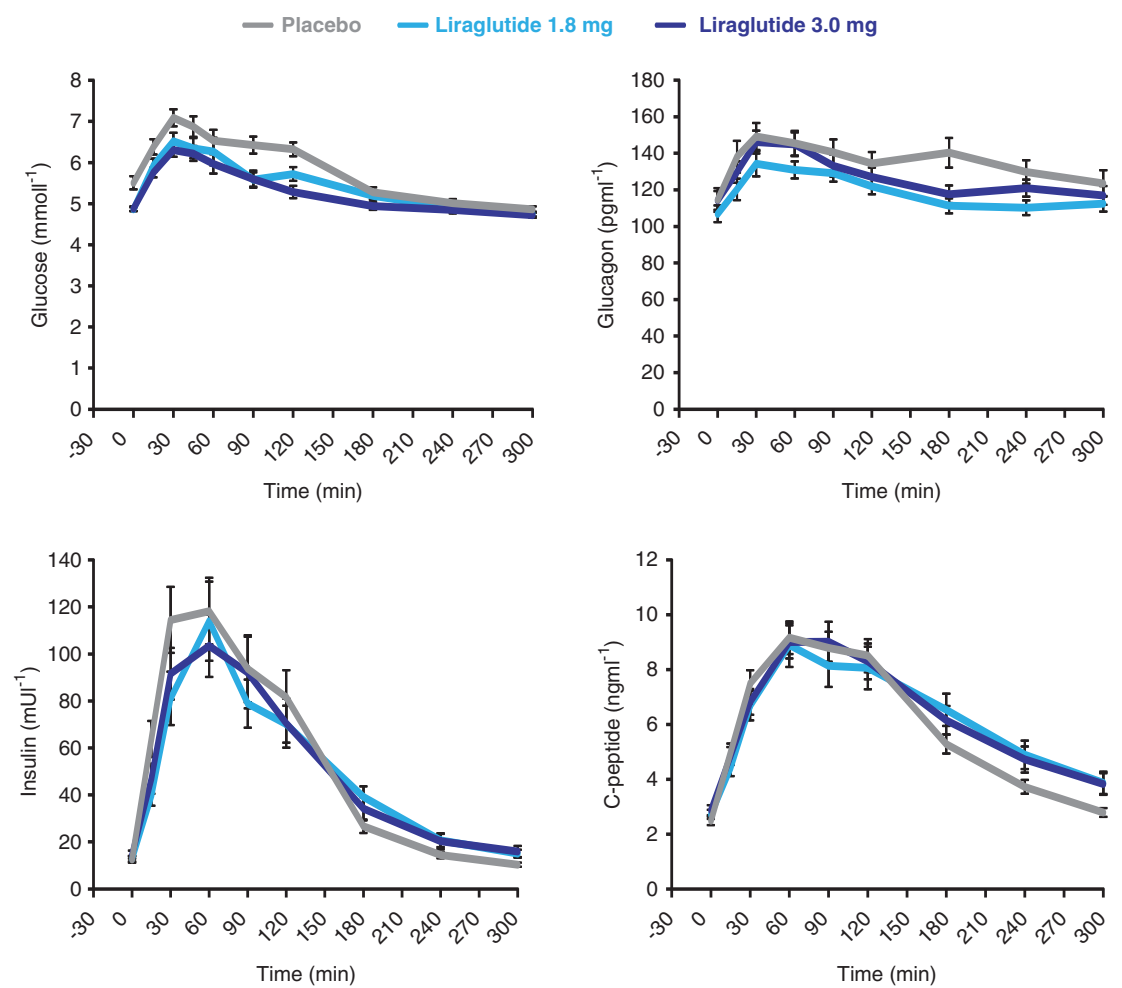

Figure 3. Effect of liraglutide and placebo on postprandial glucose, glucagon, insulin, and C-peptide concentrations. Data are presented as mean \pm s.e.

There appeared to be a treatment-related asymptomatic increase in median serum lipase activity with liraglutide compared with placebo, otherwise no clinically relevant treatment-related changes in safety laboratory measures were apparent. Mean systolic blood pressure decreased by $\sim 6-9 \mathrm{~mm} \mathrm{Hg}$ from baseline to end-of-treatment in all groups. No noticeable changes were observed for mean diastolic blood pressure. Liraglutide treatment was associated with increased mean resting pulse at end-oftreatment compared with baseline (two to three beats per min). Moreover, mean 24-h heart rate during the chamber stay was higher with both liraglutide $1.8 \mathrm{mg}(77 \pm 8$ beats per min; range 62-93) and $3.0 \mathrm{mg}$ (77 \pm 7 beats per min; range 65-89), compared with placebo ( $73 \pm 10$ beats per min; range $55-89$ ). The treatment difference versus placebo with both liraglutide $1.8 \mathrm{mg}$ (5.7 beats per $\min (95 \% \mathrm{Cl} 3.2 ; 8.1) ; P<0.0001)$ and $3.0 \mathrm{mg}$ ( 6.6 beats per min (4.0; 9.2); $P<0.0001)$ were statistically significant.

\section{DISCUSSION}

The results of this study confirmed the hypothesis of gastric emptying equivalence between liraglutide 1.8 and $3.0 \mathrm{mg}$ during the 5 -h meal test $\left(\mathrm{AUC}_{0-300 \mathrm{~min}}\right)$ after 5 weeks of treatment (at steady-state concentrations of liraglutide) in obese individuals without T2DM. Some evidence of delayed gastric emptying during the first hour of the meal test was apparent with liraglutide $3.0 \mathrm{mg}$ (a nonsignificant trend with $1.8 \mathrm{mg}$ was observed), in agreement with results from previous trials with liraglutide $1.8 \mathrm{mg}$ in T2DM. ${ }^{11,12}$ The clinical relevance of this initial delay in gastric emptying is unknown. It is considered unlikely to be important in the context of co-administered oral medications but may have contributed to the observed reductions in postprandial glucose.

Fasting plasma glucose, postprandial glucose $C_{\max }$ and 1-h AUC responses were reduced to a similar extent with both liraglutide doses versus placebo. These findings are consistent with previous trials with liraglutide at doses up to $2.0 \mathrm{mg}$ in T2DM, ${ }^{13,28,29}$ and in a phase 2 dose-finding trial in obese individuals without T2DM, ${ }^{9}$ about $30 \%$ of whom had prediabetes at baseline. In that study, liraglutide reduced the prevalence of prediabetes over 2 years by half. ${ }^{10}$ Interestingly, however, only liraglutide $3.0 \mathrm{mg}$ reduced the incremental glucose response during the 5 -h meal test ( $\mathrm{iAUC}_{0-300 \mathrm{~min}}$ ), by $\sim 26 \%$ compared with both $1.8 \mathrm{mg}$ and placebo, in the face of similar improvements in postprandial insulin, C-peptide and glucagon responses and body weight loss between liraglutide doses. Taken together, these results confirm the efficacy of liraglutide, particularly at the $3.0 \mathrm{mg}$ dose, for improved fasting and postprandial glycemic control in obese individuals without T2DM.

Both liraglutide doses were associated with similar consistent changes in all four dimensions of the overall appetite score during the 5-h meal test, reflecting reduced appetite and increased satiety. Importantly, these appetite changes were associated with a $\sim 16 \%$ lower energy intake at the subsequent ad libitum lunch with liraglutide-more than $500 \mathrm{~kJ}$ compared with placebo. Energy intake has not previously been assessed with liraglutide $3.0 \mathrm{mg}$, but in previous trials with liraglutide $1.8 \mathrm{mg}$ in T2DM, reductions in energy intake of $\sim 9-18 \%$ versus placebo were observed after short-term treatment. ${ }^{12,30}$ Moreover, a metaanalysis demonstrated a mean $12 \%(727 \mathrm{~kJ})$ reduction in energy intake during test meals performed during native GLP-1 infusion in participants with and without T2DM. ${ }^{31}$ Clinical Practice Guidelines suggest that a daily reduction in energy intake of 2.6 MJ will predict a weight loss of about $0.5 \mathrm{~kg}$ weekly (assuming no change in $\mathrm{EE}) .^{32}$

This study is the first to investigate the effects of liraglutide on 24-h EE in obese non-diabetic individuals. Twenty-four hours EE was slightly but statistically significantly reduced with liraglutide treatment (both 1.8 and $3.0 \mathrm{mg}$ ), partly explained by a treatmentrelated reduction in body weight over the 5 -week period. A previous study showed no acute effects of liraglutide $0.6 \mathrm{mg}$ on 24-h EE, as assessed by indirect calorimetry, after 3 days of 

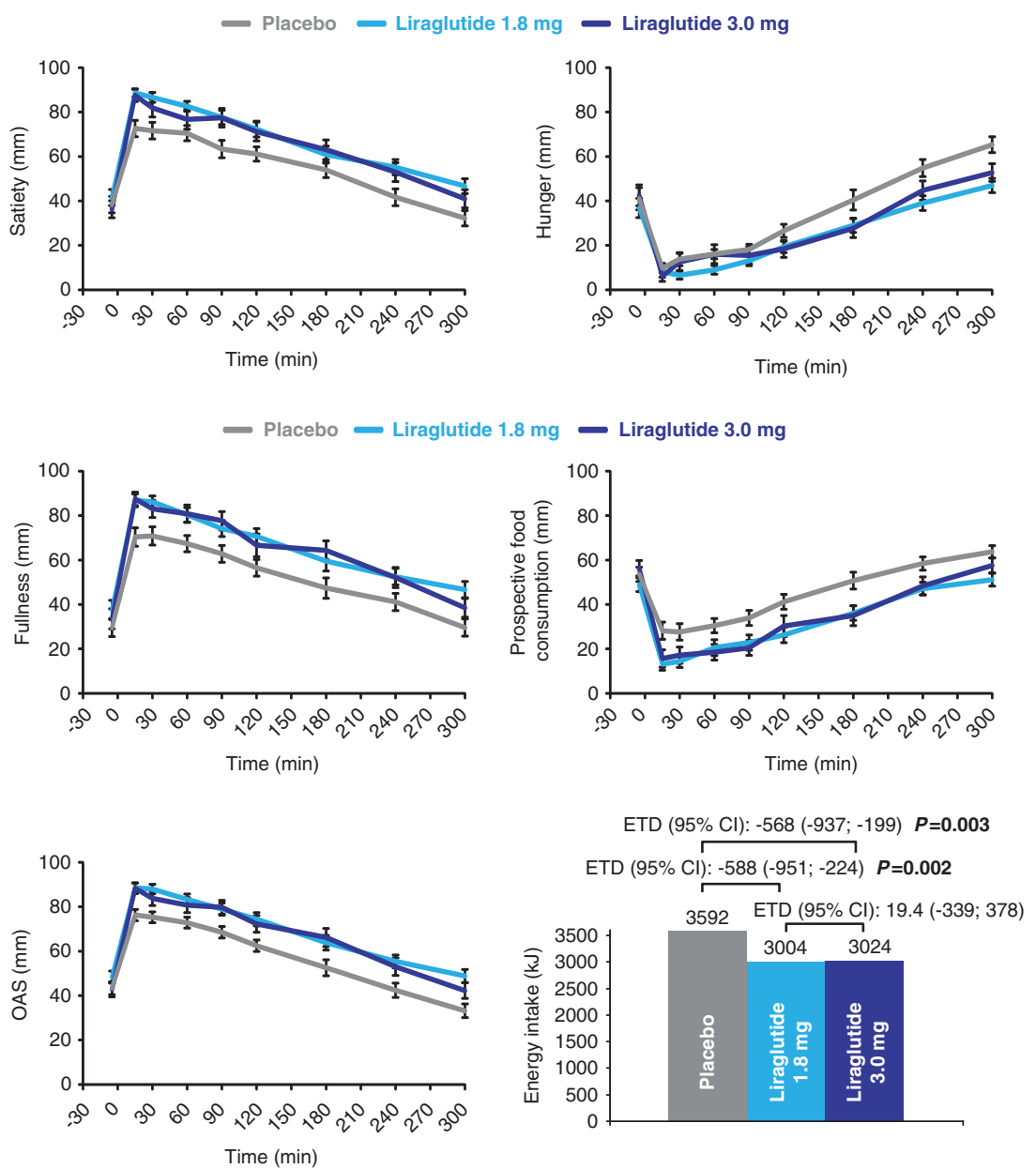

Figure 4. Appetite ratings (assessed by visual analog scale, VAS) following the breakfast meal, and energy intake during ad libitum lunch meal, served $5 \mathrm{~h}$ after breakfast. Data for energy intake are estimated means, appetite ratings are presented as mean \pm s.e. and treatment differences are calculated using the parametric linear mixed-effect model on the original outcome values. The model included effects of subject, period and treatment group and the subject effect was included as a random effect. ETD, estimated treatment difference; OAS, overall appetite score. $\mathrm{OAS}=($ satiety + fullness $+(100-$ hunger $)+(100$ - prospective food consumption $)) / 4$.

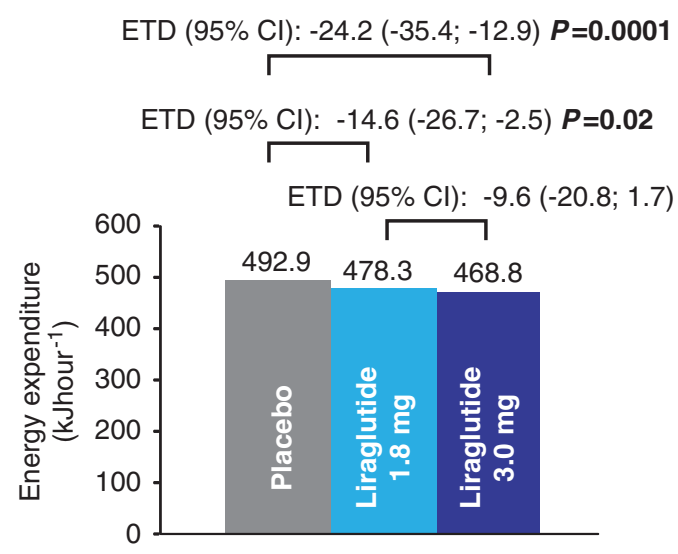

Figure 5. Total 24-h energy expenditure. Data are estimated means. Treatment differences were calculated using the parametric linear mixed-effect model including effects of period and treatment group. Subject was included as a random effect. ETD, estimated treatment difference.

treatment in T2DM. ${ }^{33}$ Likewise, subsequent studies have revealed no treatment-related changes in REE or 24-h EE in obese individuals without T2DM after at least 14 weeks of treatment with the GLP-1 receptor agonist exenatide, ${ }^{34,35}$ or in REE in T2DM after 4 weeks of liraglutide treatment ( 2 weeks on $1.8 \mathrm{mg}){ }^{12}$ In the current study, sleeping metabolic rate (representative of REE) was also slightly but statistically significantly lower with liraglutide versus placebo. Differences between the studies, mainly in methodology and treatment duration, make comparisons difficult. Despite the reduction in $\mathrm{EE}$ and a relative shift in substrate oxidation, both of which indicate a negative energy balance, it is of interest to observe that liraglutide treatment at doses of $1.8 \mathrm{mg}$ and above continues to promote satiety and reduce hunger. The durability of this response and its relevance for long-term weight maintenance remain to be determined. However, sustained 2-year weight loss with liraglutide $3.0 \mathrm{mg}$ treatment as an adjunct to diet and exercise has previously been demonstrated in obese individuals without T2DM. ${ }^{10}$

Liraglutide was generally well tolerated. As seen previously with liraglutide, the most frequently reported side effects were gastrointestinal, but dose-escalation helps to mitigate these. ${ }^{36}$ Consistent with previous trials with liraglutide and other GLP-1 receptor agonists, slight increases in resting pulse and lipase activity were observed, ${ }^{37-39}$ the clinical relevance of which remains to be determined. The decrease in urinary 24-h noradrenaline excretion was likely due to weight loss. ${ }^{40}$

Limitations of the study include the fact that it was powered for the primary end point only; therefore caution must be exercised 
when interpreting the results, as no correction for multiplicity was done. Moreover, the crossover design of the trial was incomplete; hence participants were not exposed to all treatments. Assessments were made with liraglutide concentrations at steady-state. However, as the maintenance dose is achieved by dose escalation to mitigate gastrointestinal side effects, some weight loss was observed with liraglutide during the 5-week period. An impact of this weight loss on some of the study end points cannot be ruled out.

In conclusion, this study confirmed equivalence between liraglutide 1.8 and $3.0 \mathrm{mg}$ with respect to gastric emptying over $5 \mathrm{~h}$ in obese individuals without T2DM. Although no treatment differences were observed over $5 \mathrm{~h}$, both liraglutide doses delayed gastric emptying in the first hour of the meal, though only $3.0 \mathrm{mg}$ reached statistical significance. Results suggest that liraglutideinduced weight loss is mediated via effects on appetite sensations and subsequent reduced energy intake, rather than increased $\mathrm{EE}$. Although both doses similarly improved fasting and the initial postprandial glycemia, only liraglutide $3.0 \mathrm{mg}$ improved the 5 -h incremental glucose response in this population. Ongoing clinical trials will determine the clinical implications of these findings in delaying onset of T2DM in obese individuals with prediabetes and improving glycemic control in individuals with established T2DM.

\section{CONFLICT OF INTEREST}

Liraglutide is a Novo Nordisk proprietary compound under development for weight management. JVC, EEB and WHMS declare no conflict of interest. BS, CBJ and AF are employed by and own stock in Novo Nordisk A/S.

\section{ACKNOWLEDGEMENTS}

This study would not have been possible without the research team at Maastrich University (sub-investigator Guy Vijgen, clinical dieticians Sandy Monsheimer and Karin Wings, and respiratory chamber technician Paul Schoffelen), and most importantly the commitment of the study participants. We also thank Johanna Welch, $\mathrm{PhD}$, and Angela Harper, $\mathrm{PhD}$, who provided medical writing services on behalf of Novo Nordisk A/S. The work was funded by Novo Nordisk A/S, Denmark.

\section{REFERENCES}

1 Kopelman PG. Obesity as a medical problem. Nature 2000; 404: 635-643.

2 Mokdad AH, Ford ES, Bowman BA, Dietz WH, Vinicor F, Bales VS et al. Prevalence of obesity, diabetes, and obesity-related health risk factors, 2001. JAMA 2003; 289 76-79.

3 Bays HE. Current and investigational antiobesity agents and obesity therapeutic treatment targets. Obes Res 2004; 12: 1197-1211.

4 Meier JJ, Gethmann A, Gotze O, Gallwitz B, Holst JJ, Schmidt WE et al. Glucagonlike peptide 1 abolishes the postprandial rise in triglyceride concentrations and lowers levels of non-esterified fatty acids in humans. Diabetologia 2006; 49 452-458.

5 Wettergren A, Schjoldager B, Mortensen PE, Myhre J, Christiansen J, Holst JJ. Truncated GLP-1 (proglucagon 78-107-amide) inhibits gastric and pancreatic functions in man. Dig Dis Sci 1993; 38: 665-673.

6 Flint A, Raben A, Ersboll AK, Holst JJ, Astrup A. The effect of physiological levels of glucagon-like peptide-1 on appetite, gastric emptying, energy and substrate metabolism in obesity. Int J Obes 2001; 25: 781-792.

7 Flint A, Raben A, Astrup A, Holst JJ. Glucagon-like peptide 1 promotes satiety and suppresses energy intake in humans. J Clin Invest 1998; 101: 515-520.

8 Meeran K, O'Shea D, Edwards CM, Turton MD, Heath MM, Gunn I et al. Repeated intracerebroventricular administration of glucagon-like peptide-1-(7-36) amide or exendin-(9-39) alters body weight in the rat. Endocrinology 1999; 140: 244-250.

9 Astrup A, Rossner S, Van Gaal L, Rissanen A, Niskanen L, Al Hakim M et al. Effects of liraglutide in the treatment of obesity: a randomised, double-blind, placebo-controlled study. Lancet 2009; 374: 1606-1616.

10 Astrup A, Carraro R, Finer N, Harper A, Kunesova M, Lean ME et al. Safety, tolerability and sustained weight loss over 2 years with the once-daily human GLP-1 analog, liraglutide. Int J Obes (Lond) 2011; 36: 843-854.
11 Kapitza C, Zdravkovic M, Hindsberger C, Flint A. The effect of the once-daily human glucagon-like peptide 1 analog liraglutide on the pharmacokinetics of acetaminophen. Adv Ther 2011; 28: 650-660.

12 Horowitz M, Flint A, Jones KL, Hindsberger C, Rasmussen MF, Kapitza C et al. Effect of the once-daily human GLP-1 analogue liraglutide on appetite, energy intake, energy expenditure and gastric emptying in type 2 diabetes. Diabetes Res Clin Pract 2012; 97: 258-266.

13 Flint A, Kapitza C, Hindsberger C, Zdravkovic M. The once-daily human glucagonlike peptide-1 (GLP-1) analog liraglutide improves postprandial glucose levels in type 2 diabetes patients. Adv Ther 2011; 28: 213-226.

14 Peterson GE, Pollom RD. Liraglutide in clinical practice: dosing, safety and efficacy. Int J Clin Pract Suppl 2010; 167: 35-43.

15 World Medical Association. Declaration of Helsinki. Ethical Principles for Medical Research Involving Human Subjects. Last amended by the 59th WMA Assembly, Seoul. Oct-2008. JAMA 2000; 284: 3043-3045.

16 ICH Harmonised Tripartite Guideline. International Conference on Harmonisation 1996http://www.ich.org/fileadmin/Public_Web_Site/ICH_Products/Guidelines/ Efficacy/E6_R1/Step4/E6_R1_Guideline.pdfAccessed 14 Nov 2012

17 Agerso $H$, Jensen LB, Elbrond B, Rolan P, Zdravkovic M. The pharmacokinetics, pharmacodynamics, safety and tolerability of NN2211, a new long-acting GLP-1 derivative, in healthy men. Diabetologia 2002; 45: 195-202.

18 Willems M, Quartero AO, Numans ME. How useful is paracetamol absorption as a marker of gastric emptying? A systematic literature study. Dig Dis Sci 2001; 46: 2256-2262.

19 Sanaka M, Kuyama Y, Yamanaka M. Guide for judicious use of the paracetamol absorption technique in a study of gastric emptying rate of liquids. J Gastroenterol 1998; 33: 785-791.

20 Flint A, Raben A, Blundell JE, Astrup A. Reproducibility, power and validity of visual analogue scales in assesment of appetite sensations in single test meal studies. Int J Obes Relat Metab Disord 2000; 24: 38-48.

21 Schoffelen PF, Westerterp KR, Saris WH, Ten HF. A dual-respiration chamber system with automated calibration. J Appl Physiol 1997; 83: 2064-2072.

22 Weir JB. New methods for calculating metabolic rate with special reference to protein metabolism. J Physiol 1949; 109: 1-9.

23 Frayn KN. Calculation of substrate oxidation rates in-vivo from gaseous exchange. J Appl Physiol 1983; 55: 628-634.

24 Westerterp Kr, Wilson SA, Rolland V. Diet induced thermogenesis measured over $24 \mathrm{~h}$ in a respiration chamber: effect of diet composition. Int J Obes Relat Metab Disord 1999; 23: 287-292.

25 Ravussin E, Lillioja S, Anderson TE, Christin L, Bogardus C. Determinants of 24-hour energy expenditure in man. Methods and results using a respiratory chamber. J Clin Invest 1986; 78: 1568-1578.

26 Human energy requirements. Report of a joint FAO/WHO/UNU expert consultation. FAO: food and nutrition technical report series 1. FAO/WHO/UNU 2004.

27 Schrauwen P, van Marken Lichtenbelt WD, Westerterp KR. Energy balance in a respiration chamber: individual adjustment of energy intake to energy expenditure. Int J Obes Relat Metab Disord 1997; 21: 769-774.

28 Vilsboll T, Zdravkovic M, Le-Thi T, Krarup T, Schmitz O, Courreges JP et al. Liraglutide, a long-acting human glucagon-like peptide-1 analog, given as monotherapy significantly improves glycemic control and lowers body weight without risk of hypoglycemia in patients with type 2 diabetes. Diabetes Care 2007; 30: $1608-1610$.

29 Blonde L, Russell-Jones D. The safety and efficacy of liraglutide with or without oral antidiabetic drug therapy in type 2 diabetes: an overview of the LEAD 1-5 studies. Diabetes Obes Metab 2009; 11(Suppl 3): 26-34.

30 Flint A, Kapitza C, Zdravkovic M. The once-daily human GLP-1 analogue liraglutide impacts appetite and energy intake in patients with type 2 diabetes after short-term treatment. Diabetes Obes Metab 2013; 15: 958-962.

31 Verdich C, Flint A, Gutzwiller JP, Naslund E, Beglinger C, Hellstrom PM et al. A meta-analysis of the effect of glucagon-like peptide-1 (7-36) amide on ad libitum energy intake in humans. J Clin Endocrinol Metab 2001; 86: 4382-4389.

32 Ayyad C, Andersen T. Long-term efficacy of dietary treatment of obesity: a systematic review of studies published between 1931 and 1999. Obes Rev 2000; 1: 113-119.

33 Harder $\mathrm{H}$, Nielsen L, Tu DT, Astrup A. The effect of liraglutide, a long-acting glucagon-like peptide 1 derivative, on glycemic control, body composition, and 24-h energy expenditure in patients with type 2 diabetes. Diabetes Care 2004; 27: 1915-1921.

34 Dushay J, Gao C, Gopalakrishnan GS, Crawley M, Mitten EK, Wilker E et al. Short-term exenatide treatment leads to significant weight loss in a subset of obese women without diabetes. Diabetes Care 2012; 35: 4-11.

35 Bradley DP, Kulstad R, Racine N, Shenker Y, Meredith M, Schoeller DA. Alterations in energy balance following exenatide administration. Appl Physiol Nutr Metab 2012; 37: 893-899. 
36 Neumiller JJ, Campbell RK. Liraglutide: a once-daily incretin mimetic for the treatment of type 2 diabetes mellitus. Ann Pharmacother 2009; 43: 1433-1444.

37 Garber A, Henry R, Ratner R, Garcia-Hernandez PA, Rodriguez-Pattzi H, Olvera-Alvarez I et al. Liraglutide versus glimepiride monotherapy for type 2 diabetes (LEAD-3 Mono): a randomised, 52-week, phase III, double-blind, paralleltreatment trial. Lancet 2009; 373: 473-481.

38 Devries JH, Bain SC, Rodbard HW, Seufert J, D'Alessio D, Thomsen AB et al. Sequential intensification of metformin treatment in type 2 diabetes with liraglutide followed by randomized addition of basal insulin prompted by A1C targets. Diabetes Care 2012; 35: 1446-1454.
39 Lando HM, Alattar M, Dua AP. Elevated amylase and lipase in patients using GLP-1 receptor agonists or DPP-4 inhibitors in the outpatient setting. Endocr Pract 2012; 18: $1-16$.

40 Rosenbaum M, Hirsch J, Murphy E, Leibel RL. Effects of changes in body weight on carbohydrate metabolism, catecholamine excretion, and thyroid function. Am J Clin Nutr 2000; 71: 1421-1432.

(c) (i) $\ominus$ This work is licensed under a Creative Commons Attributioncc. NonCommercial-NoDerivs 3.0 Unported License. To view a copy of this license, visit http://creativecommons.org/licenses/by-nc-nd/3.0/

Supplementary Information accompanies this paper on International Journal of Obesity website (http://www.nature.com/ijo) 